\title{
PARTICULARITIES OF SOLVING THE PROBLEM OF SUSTAINABLE DEVELOPMENT OF CHROMITE UNDERGROUND MINING AT DEEP HORIZONS BY MEANS OF COMBINED GEOTECHNOLOGY
}

\author{
David Kaplunov ${ }^{1}$, Dosanbay Bekbergenov ${ }^{2 *}$ and Gulnar Djangulova ${ }^{2}$ \\ ${ }^{1}$ Institute of Comprehensive Exploitation of Mineral Resources, Moscow, Russia. \\ ${ }^{2}$ Mining Institute after D.A. Kunayev, Almaty, Kazakhstan.
}

\begin{abstract}
Annotation. The paper covers the particularities of development of Don chromite field and improvement of applied technologies of underground mining using uncontrolled caving. The weakest point of the technology of uncontrolled caving and any other similar structures is mining operations under the caved mass that considerably affects the stability of mine workings and their safety during the whole period of stoping. This issue is one of the most important and urgent, especially at the transition of mining operations to deeper levels where technological particularities of the minefield are getting more complicated. Therefore, the Project Development and Substantiation of Parameters of Combined Geotechnology for Safe and Sustainable Development of Chromite Mineral Resource Mining for underground mining will be a new technological solution ensuring the replacement of exhausted mineral resources in the Republic of Kazakhstan in the conditions of transition of mining operations to deeper levels. Further development at the combined and sequential underground mining operations using the system of uncontrolled caving and the system of horizontal layers with stowing is essential. Key words: geotechnology, development system, sustainable development, chromite mining.
\end{abstract}

\section{Introduction}

The mining industry in Kazakhstan takes one of the leading positions and Kazakhstan is one of 15 leading mining countries and the second chromite mining nation after the SAR [1-3].

The most significant representatives that widely apply the caving systems are ore miners of Donskoy mining and processing plant developing thick ore deposits of the fields confined within the southern edge of Kempirsay massif that includes over 160 fields,

*Corresponding author: kdbekbergen@mail.ru 
occurrences and chromite mineralization. At that, the prevalent part of ore deposits, $93 \%$ is mined underground [4-6].

In the conditions of scarcity and impossibility to replace mineral reserves, of special significance at their development is the task of sustainable use of subsoil that requires the improvement and application of new options of underground mining technology.

As the second working develop in the mentioned conditions and the scope of preproduction and temporary working increases and more confined stopes are created, there arises a need in more rational control of processes, in reliable structural elements of the development system, selection of methods and means of mine working support and finally in effective and safe system of development of ore deposits.

Therefore, it is necessary to understand the essence of these complications and to make reasonable choice of process charts based on regularities of mining technical processes associated with the development and to determine their parameters in order to exclude accidents and ensure rational subsoil management.

\section{Materials and Methods}

The technology of uncontrolled caving at Donskoy mining and processing plant is mainly applicable in the medium and low-stability rocks which is very typical of the Don chromite fields. Their distinguishing feature is high fracturing of the rock mass, various fracture systems and spatial orientation. All these eventually stipulate low strength of ore bodies and the host rock mass. In this connection, one of the major and most urgent issues at the underground development of chromite fields is the provision of stability and reliability of operation of development and temporary workings during the whole period of operation.

The ores of the Kempirsay field are classified as easily concentrated. There are two types of ore grades [7]: high-grade with over $45 \%$ of $\mathrm{Cr} 2 \mathrm{O} 3$, and run-of mine ore. The raw ore is mined underground (94.1\%) at the mines Molodezhnaya and the Tenth Anniversary of Kazakhstan Independence (DNK), as well as using open-cast mining (5.9\%) at the Yuzhnyi open pit.

The chromite ore is mined underground using the system of uncontrolled caving (Figure 1) which is class 2 of the development system according to Prof. V.R. Imenitov's classification.
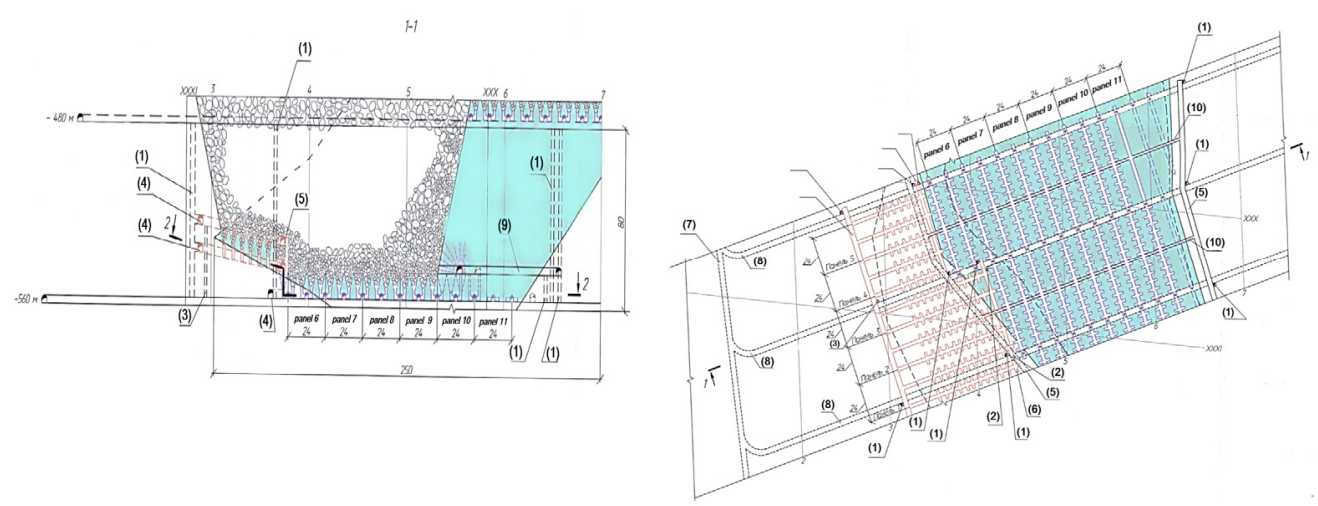

1 - VMR (Ventilation manway raise); 2 - Ore chute; 3 - Rock chute; 4 - Prefabricated air level; 5 Air level; 6 - Storage drift; 7 - Haulage ort; 8 - Ort; 9 - Air orts; 10 - Household ort; 11 - Panel

Fig.1. Development of Don chromite reserves using the technology of uncontrolled caving 
This development technology of uncontrolled caving is characterized by gradual separation of the ore from the rock mass under the proper weight and mine pressure without forced explosion [8]. In the low part of the block, under the caved ore mass, the network of drawing workings is laid that are separated from each other by small pillars. Above the draw horizon, a horizontal exposure is formed using an explosion - an undercut onto which the mass is caved under the force of the proper weight and pressure of overlying rock by means of its cracking in the conditions of unstable fractured ores.

There are four stages of the process in the system of uncontrolled caving:

- Formation of a blasted slot and beginning of undercut formation;

- Initiation of Ouncontrolled caving;

- Development of uncontrolled caving of ore and host rocks;

- Uncontrolled caving reaches the surface.

The mining geological conditions most favorable for the application of the system of uncontrolled caving are: possibility of caving of the surface and overlying stratum of host rocks, and considerable fracturing of the ore body.

The technology of uncontrolled caving is of great interest due to its cheapness and simplicity.

The case history of the technology at underground mines of the company De Beers (South Africa) revealed that the cost of mining is commensurate with the open-cast mining cost. Of special interest is the practice of those working with this technology and belonging to the authors [9], as well as the description of experience of efficient operation of several foreign mining companies: diamond mines "Finch", "Premier" and "Koffiefontein" (South Africa), copper-nickel mine "North Sparks" (Australia), copper-molybdenum mine "Henderson" of the company "Climax" (USA) and mine "El Teniente" (Chili).

The development system of uncontrolled caving has long been considered as the main mining technology of chromite ores at the mines of Donskoy mining and processing plant. The effectiveness of this system is due to the solving of geomechanical tasks related to the stability of mine workings at the stope sill, the reduction in the abutment pressure that tends to increase as the second working begins, the selection and substantiation of optimal design of the stope sill, the sequence of development of adjacent production units and timetable of ore drawing.

The mining geological and mining technical conditions of chromite mining are classified as very complicated in view of instability and high fracturing of ores and host rocks. The engineering geological description of the field developed within the DNK mine is characterized by the hardness factor of host rocks around $8 \div 10$, and ores, $6 \div 8$ due to the structural weakening and volumetric scale effect. In fact, the hardness factor of ores and rocks does not exceed 4-6.

These properties of the rock mass create certain conditions for the application of the development system using uncontrolled caving. However, the instability and tendency to uncontrolled caving are the source of constant manifestation of mine pressure during all mining operations at the mines of Donskoy mining and processing plant. In most cases, despite double additional supports, the supports of development headings and stopes are destroyed and stop working long before the end of second working. In fact, stump pillars, which are the elements of the stope sill, do not serve as such because they are located in a kind of "loose condition because of initial intensive fracturing of the rock mass and dynamic impact of explosions on it. Thus, these pillars as if "lie" on the support of stopes with all their weight and the weight of the whole thickness of caved rocks and overlying rocks and deform them practically pressing them in the ground. Therefore, to excavate the remained ore mass it is necessary to pay extremely undesirable additional expenses for timber relieving (sometimes even repeatedly). These measurements negatively affect the timing of mining operations and rhythm of the mine activity. 
Therefore, it is possible to state that despite all the advantages such as maximum productive capacity and the lowest cost, the application of technology of uncontrolled caving of host rocks at the mines of Donskoy mining and processing plant is rather a forced necessity than an effective technical solution of rational sustainable mining in the absence of any other decent option.

In addition to the above-listed major problems, there are less urgent issues arising right at the realization of development and second working in a block, such as combat against inrushes of rocks (ore) at the road heading, premature inrush of overlying rocks into draw points from so-called "tubes" resulted from uneven mineralization and consolidation ability, humidity and looseness of ores, issues related to loss of time at the elimination of overhung boulders, difficulties with ore drawing timetable, unsatisfactory accuracy of losses evaluation and ore dilution for the developed block.

The following institutes and laboratories have performed works with regard to the selection of technological options of field development, finding ways to overcome negative sides of mining geological conditions and increase the overall efficiency of underground chromite mining: Mining Institute after D.A. Kunayev, Mining Institute of Ural Department of the Russian Academy of Sciences, Ust-Kamenogorsk Institute "Kagiprotsvetmet", Institutes VIOGEM and VSEGINGEO (All-Russian Research Institute of Hydrogeology and Engineering Geology) as well as the resources of the research group of the plant. This research has brought expected results, and complied with the requirements of that time. At the present time, further chrome mining and increase in production capacities at the mines of Donskoy mining and processing plant take place due to the involvement of deeper deposits. Transition to deeper levels results in harder mining technical conditions, mainly geomechanical and technological ones.

A new technical solution by the Kasgiprotsvetmet Institute was the application of the mining technology with consolidating stowing at the transition of mining operations to deeper levels of the DNK mine. The project [10] corrected the stripping scheme, the order of preparation and development of reserves of the Millionnoye and Almaz-Zhemchuzhina fields. The application of the combined geotechnology suggests the separation of the ore field in order to develop one part of reserves using horizontal descending layers with stowing (Figure 2) and another part of the field, using the development system of uncontrolled caving.
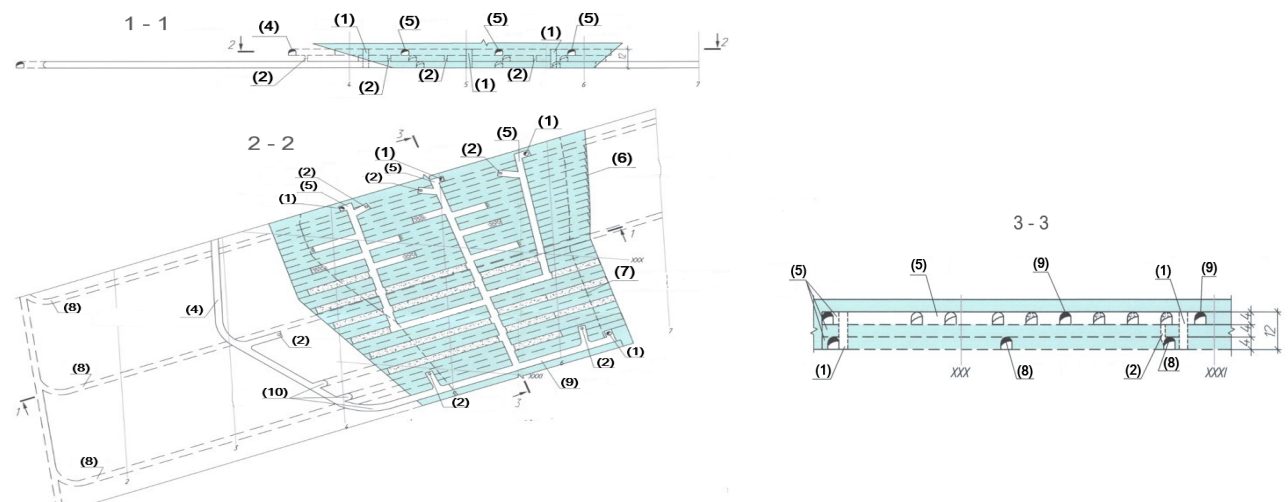

1 - VMR (Ventilation manway raise); 2 - Ore chute; 3 - Load-haul drift; 4 - Haul drift for selfpropelled equipment; 5 - Stope drift; 6 - Contour of reserves mining using the primary layer; 7 Contour of reserves mining using the final layer; 8 - Ort; 9 - Cut ort; 10 - Cross slits stope drift

Fig. 2. Development of Don chromite reserves using the system of horizontal layers with stowing according to the Kazgiprotsvetmet project 
There is a positive experience of road heading in the stowing, for example, at underground mines of JSC GMK Norilskiy Nickel.

According to the results of performed research and published works in scientific foreign editions [11] as well as the review of the practice at the mines of Donskoy mining and processing plant, despite the development of lower levels of the chromite field of Donskoy mining and processing plant in the evolving conditions, it is quite realistic to transit to artificial stope sills. And currently in line with the Kazgiprotsvetmet project this type of the stope sill is necessary. To tackle the issues of designing artificial concrete stope sills, the staff of the Mining Institute after D.A. Kunayev developed the design of artificial concrete stope sill on a stope sill-support basis ensuring sufficient reliability, stability and operability of scraping drifts. The developed design of the stope sill represents the main designed structural elements, sequence of road heading of service and main workings and the order of erection of concrete support [12].

The Kazgiprotsvetmet Institute has developed the project of transition of mining operations to the lower levels of the mines of Donskoy mining and processing plant using the geotechnology combining the application of development systems using uncontrolled caving and horizontal layers with stowing.

Up to the present no study of such kind of combined geotechnology has been done. Guided by the significance of this direction for mining production, in line with the Decision of the National Academic Council of the Republic of Kazakhstan with regard to the program Grant Financing of Scientific Research for the years 2018-2020, the Mining Institute after D.A. Kunayev began the research work on the subject: Development and Substantiation of Parameters of Combined Geotechnology for Safe and Sustainable Development of Chromite Mineral Resource Mining at Deep Levels.

\section{Results and discussion}

The principles and strategies of sustainable development ensure the long-term existence and development of production with due account for the environment based on the targeted controlled economic growth. For this very reason many authors in their practice connects the geotechnological issues with the environmental problems of the mining industry [13].

At the same time, the measures aimed at the formation of the general policy of sustainable development of mining and smelting industry become more significant in line with current requirements of this field. An important condition for successful realization of the Plan of Actions of the World Summit on Sustainable Development (Johannesburg, 2002) related to the mining and smelting branches of industry is the principles formulated regarding the issues of sustainable development of the mining industry of the Republic of Kazakhstan [14]:

First of all, the satisfaction of the main needs of the current and future generations and conservation of existing ecosystems and restoration of the disturbed ones. Development of mineral resources using environmentally clean and safe mining processing technologies with due account for the balance of the government, society and representatives of mining business.

In view of the mentioned solution to the problem, the development of combined geotechnology for safe and sustainable development of chromite mining requires certain transition from setting the task of application of underground geotechnology depending on the economic growth to setting the task and providing economic development, substantiation of physical and technical parameters of the combined geotechnology. Such model includes technological solutions that ensure the replacement of exhausted mineral resources in the Republic of Kazakhstan; in this particular case, it is based on the development and substantiation of parameters of combined geotechnology in the conditions 
of transition of mining operations to deeper levels at simultaneous and consecutive underground mining operations using the development system of uncontrolled caving and horizontal layers with stowing.

An adequate complex of processes for sustainable development of the combined geotechnology depends on a large number of factors.

The analysis of research by contemporary authors testifies the availability of various approaches to the identification of factors of sustainable development of underground mining geotechnology.

A combination of factors affecting the extent of sustainability of development of underground mining geotechnology by various kinds of ores is divided into the management level, time factor management and technical maintenance.

It is worth noting that majorly the factors of sustainable development are backbone, and only when the impact of these factors is comprehensively accounted for, it is possible to achieve the goals of sustainable development of underground ore production using the combined geotechnology.

The methodology of development and substantiation of parameters of the combined geotechnology for safe and sustainable development of chromite mining at deep levels must meet the safety requirements within the proposed combined geotechnology, requirements of technological properties and cost effectiveness, i.e. profitability of the development and combined geotechnology at the development of reserves at the transition of mining operations to deeper horizons.

\section{Conclusion}

The above conditions and factors will contribute to the realization of the new project idea related to the combined geotechnology of chromite mining at deep levels, namely the creation of designs with the stable reinforced-concrete platforms with artificial stope sill made of concrete consolidating stowing for producing blocks. In this way the platform is created for the system of uncontrolled caving capable of bearing high mine pressure and ensuring increased stability of haul crosscuts as well as the safety of draw and haulage workings during the whole period of block development for independent ore transportation.

Based on the foregoing, the problem of sustainable development of chromite mining at deep levels at the companies of Donskoy mining and processing plant requires the development and substantiation of parameters of the artificial stope sill of the system with uncontrolled caving at deep horizons of the DNK mines on the basis of the study of reasons for the rock mass caving around development and transportation workings at deep levels of mines belonging to Donskoy mining and processing plant.

Along with this, another important and urgent issue is the forecasting of risks to ensure sustainable ore mining.

\section{References}

1 Ibragim Edilbaev. Revival (1995-2005), (2004).

2 Guidelines on Claculation of Loads on the Support of Mine Workings in the Conditions of Mines of the Donskoy mining and processing plant. (Karaganda - 2002).

3 Leonid Zherebko, Lyazzat Shamganova, Gulnar Jangulova. Specific Character of Don Chromites Development in Complex Mining and Geological Conditions. The $16^{\text {th }}$ International Multidisciplinary Scientific Geoconference. Exploration and Mining. Mineral Processing. Sgem 30 June - 6 July (2016). 
4 Dosanbai Bekberenov, Gulnar Dzhangulova. Geomechanical Nature and Technological Particularities of Application of the Uncontrolled Caving Technology at Deep Levels of the DNK Mine of Donskoy mining and processing plant / The International Scientific Technical Conference "Problems and Ways of Innovative Development of Mining and Smelting Industry", Tashkent 27-29 November (2014).

5 Ibragim Edilbaev, Marat Bitimbaev, Leonid Zherebko. Development of the Caved Zone in the Superincumbent Rock at the Development of Ore Deposits Using the System of Uncontrolled Caving at Fields of Don Chromites. Scientific and Technical Provision of Mining Production. Collection of Proceedings of the Mining Institute after D.A. Kunayev, No 68, Part I. Almaty, (2004).

6 Kabden Nugmanov, Leonid Zherebko. Stress Condition of the Mass in the Zone of Road Heading, Scientific and Technical Provision of Mining Production. Proceedings of the Mining Institute after D.A. Kunayev, Almaty, V.65 (2004).

7. Dosanbai Bekbergenov, Ayan Toktarov. Problems of Development of Deep Horizons of Chromite Ores of Kempirsay Mass. (Collection of proceedings of the branch Mining Institute after D.A. Kunayev, volume 84, Almaty, 2013).

8 Evgeniy Kuzmin, Uzbekova. Uncontrolled Caving of Ore at the Underground Ore Mining: Tutorial. - M.: Press of the Moscow Mining University, (2006).

9 Stefan Nadolski, Mike Samuels1, Bern Klein, Craig J.R. Hart. Evaluation of Bulk and Particle Sensor-Based Sorting Systems for the New Afton Block Caving Operation. Minerals Engineering 121 (2018).

10 “Kazgiprotcvetmet”, Project, volume 2, book 3, Ust-Kamenogorsk. (2003).

11 Rafiee, Ataei, Khaloo Kakaie, Jalali, Sereshki, Numerical Modeling of Influence Parameters in Cavabililty of Rock Mass in Block Caving Mines. International Journal of Rock Mechanics and Mining Sciences, 105 (2018).

12 Gulnar Dzhangulova, Leonid Zherebko, Larisa Pivovarova. The RK Patent 79933. The Method of Erection of the Artificial Stope Sill at the Development of Unstable Ore Deposits at Great Depth (27.01.2012).

13 Yuriy Galchenko, Leonid Burtsev. Environmental Component of Sustainable Development as Applied to Underground Ore Mining. Materials of the International Symposium "Miner's Week - 98" (Seminar 4, MGGU, 1998).

14 David Kaplunov, Yukov. The Principles of Sustainable and Environmentally Balanced Subsoil Development Based on the Combined Geotechnology, (Mining Magazine No 11, 2015). 